\title{
Air quality monitoring and management for the industrialized Highveld region of South Africa
}

\author{
G. V. Mkhatshwa \\ Eskom Research and Innovation Department, South Africa
}

\begin{abstract}
The rapid economic growth in developing countries has led to increases in energy consumption patterns and industrial activity leading to air quality degradation. Due to the rapid industrial expansion in South Africa, there has been a great demand for increased electrical generation. About $89 \%$ of electricity generated in the Southern African Development Community (SADC) region is from coal, mostly produced in South Africa. Eskom generates 95\% of the electricity used in South Africa and has undertaken extensive air quality monitoring on a regional basis since the 1970s. The aim of the monitoring is to assist Eskom in the assessment of environmental impacts related to its activities and to facilitate appropriate control strategies. The South African Highveld is impacted by emissions from motor vehicles, heavy and light industry, power stations, coal mining and numerous large townships and informal settlements. This paper presents air quality monitoring and management trends adopted by Eskom for the past 20 years over the Highveld region of South Africa and how these have changed with time. An overview of air quality monitoring methods is presented and ambient air quality trends over a minimum of a 10-year period at specific monitoring stations are discussed. Generally ambient concentrations of pollutants such as sulphur dioxide $\left(\mathrm{SO}_{2}\right)$, nitrogen oxides $(\mathrm{NOx})$ and fine particulate matter (FPM) have been decreasing with time in the Highveld region. This can be attributed mainly to control strategies adopted by Eskom and to the electrification of households.
\end{abstract}

Keywords: Eskom, electricity, power stations, Highveld, air quality, monitoring, Elandsfontein, Palmer, Leandra, pollutants. 


\section{Introduction}

Since the 1970s Eskom has undertaken extensive air quality monitoring on a regional basis. The aim of this monitoring is to assist Eskom in the assessment of environmental impacts related to its activities and to facilitate appropriate control strategies (Rorich and Galpin [1]).

Although the highest levels of air pollution at ground level are still found in informal settlements in South Africa, it is the contribution that industry makes to the already polluted air that is a contested issue. Industrial and power station emissions influence a much greater area, however, and the detrimental effects of the pollutants on ecosystems have yet to be properly assessed. Industrial activities in the Mpumalanga Highveld introduce a wide range of anthropogenic primary pollutants into the atmosphere. During coal combustion processes carbon dioxide, carbon monoxide, hydrocarbons, nitrogen oxide and nitrogen dioxide, sulphur dioxide and soot are released into the atmosphere (Eskom [2]). Other major source categories of anthropogenic gases and aerosols over the Highveld are metallurgical processes, biomass burning, mining activity, smouldering dumps and domestic combustion.

The economy of the Highveld region (figure 1) is based primarily on mining, agriculture, forestry and tourism and about $44 \%$ of all commercial plantations in South Africa are in this region. The economics of locating power stations near coalmines has dictated that $78 \%$ of Eskom's electricity energy comes from the Highveld region (Eskom [3]). Atmospheric pollution on the South African Highveld is perceived as a concern because of the combination of heavy industry, motor vehicle emissions, domestic fuel combustion and climatic features that prevail in the region. The frequent occurrence of surface inversions (80-90\% of days in winter months) permits the accumulation of pollutants near ground level (van Tienhoven [4]). Although industrial stacks and those of power stations in particular, are generally able to emit gaseous and particulate pollutants over the boundary layer, looping and fumigation of plumes may occur under convective conditions.

\section{Air quality monitoring trends in the Highveld}

The most heavily industrialized area in South Africa is the Central Mpumalanga (Highveld), which is impacted by emissions from motor vehicles, heavy and light industry, power stations, coal mining and numerous large townships and squatter settlements. Eskom has, for the past two decades, undertaken extensive ambient air quality monitoring in this region and has data sets dating as far back as the early 1980 s.

Ambient air quality monitoring is conducted by the air quality team in Eskom's Research and Development Department (ERID). Routine station visits are done on a two weekly basis. During the visits, data that was stored on the data logger during the previous two weeks of monitoring is downloaded onto a laptop computer and returned to Eskom, where it is transferred onto a central 


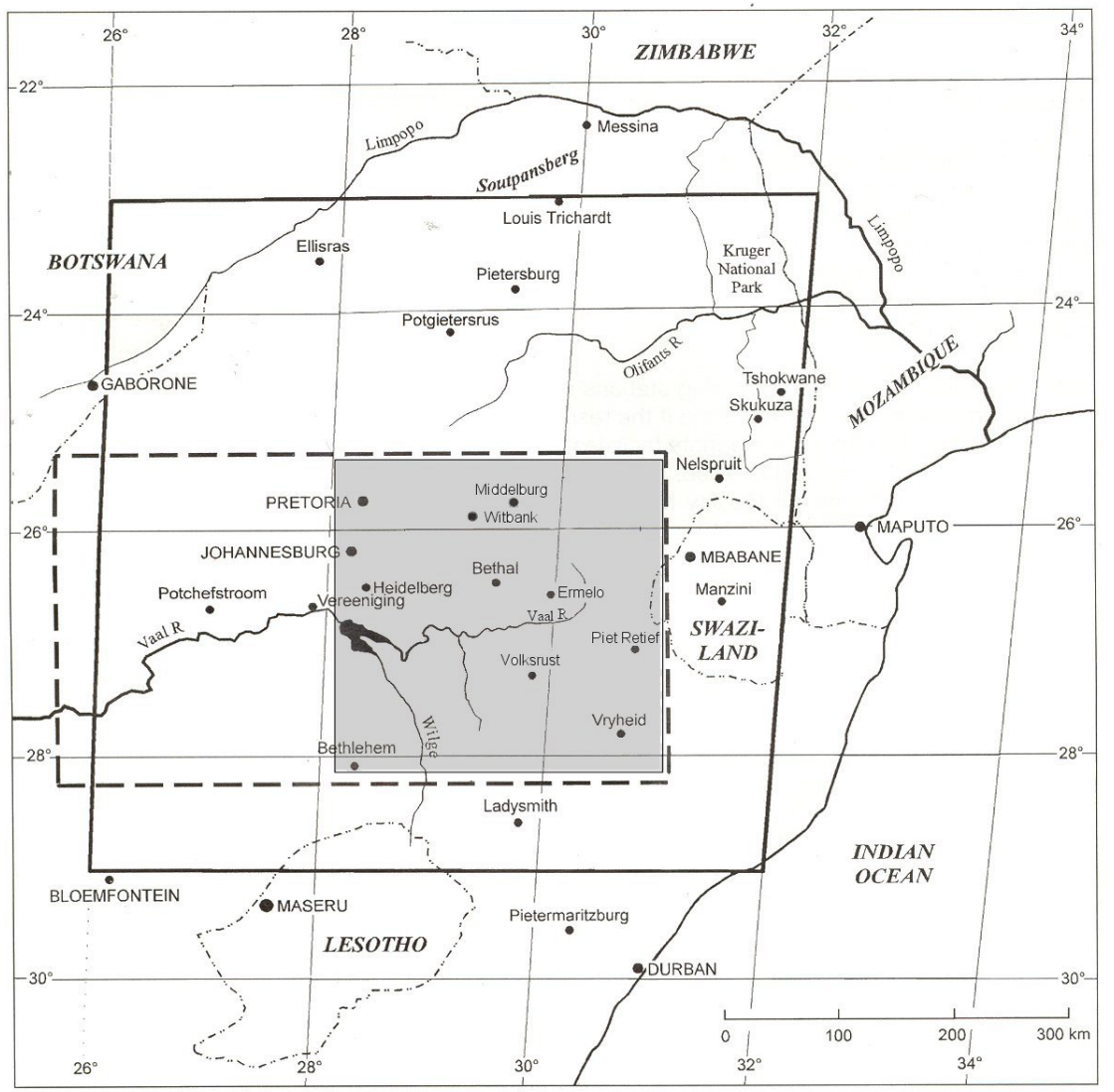

Figure 1: $\quad$ Highveld region (shaded area) as defined in Held et al. [5].

computer for processing, editing and verification. The processing, editing and verification process is carried out by expert assessment using the site logbook and site notes. After verification, copies of both the raw data and verified data are archived for report generation and future reference.

Analyzer zero and span checks and dynamic calibration audits are carried out on each of the analyzers at routine intervals and the discrepancies logged, these calibration checks can then be used to assist in data verification and validation at Eskom. This is possible as the analyzers are corrected to the audit concentrations after the initial checks if required. The air quality monitoring station internal temperature and mains voltage are continuously monitored and logged. These parameters are not monitored for compliance but for data verification purposes only.

Eskom recognized the importance of credible data and assisted local authorities in establishing accreditation of laboratories and monitoring networks in South Africa through the South African National Accreditation System (SANAS). Eskom uses the SANAS guideline figure of $80 \%$ per parameter 
monitored as a standard for representative data capture. This describes the required completeness of the data set for the reporting of averages, which is defined as $80 \%$. This figure is based on standard arithmetic calculations. The completeness calculations for data sets exclude zero and span data and times where service and/or maintenance is being conducted on the instruments in question.

Data availability is a management definition related to system reliability. The availability target is not set in terms of data quality criteria and has no associated quality objectives. A target of $90 \%$ availability has been set for performance evaluation. Availability is reported per station as a measure of total station uptime. The measure is an average of the uptime for all variables monitored in the station but excludes quality control check data (Eskom [6]).

An Environmental metadatabase for environmental research datasets has been established to ensure that Eskom's data is being utilized to its full potential by presenting the history of Eskom's environmental monitoring activities. The metadatabase provides information about data available within the environmental sciences group and gives descriptive information on the quality and characteristics of air quality data. This metadatabase gives detailed information on the monitoring sites; the pollutants and meteorological parameters measured at each site; site performance; annual percentage data capture; collection methods and general feel of logistics relating to the running of each monitoring site.

\subsection{Monitoring progression}

Monitoring of Eskom's ambient air quality began in 1978 using 2 Mobile units for monitoring $\mathrm{SO}_{2}$, the data was stored on magnetic tape; in 1979 Eskom set up 9 remote stations for $\mathrm{SO}_{2}$ using strip chart recorders and in the very same year the first conference paper introducing monitoring work done by Eskom was presented. In 1983, 22 remote stations for $\mathrm{SO}_{2}$ using PC logging facilities were set up and from 1984 onwards selective introduction of NOx nephelometers and ozone monitors has been done at almost all Eskom monitoring sites (Turner [7]). In 1989 the monitoring network was rationalised and reduced to 5 research stations with additional pollution parameters being monitored.

\subsection{Ambient air quality trends}

Long term trends of $\mathrm{SO}_{2}$, NOx and FPM (PM10) have been investigated at 3 sites in the Highveld; Elandsfontein (considered to be of prime importance to regional impact studies and pollution trend analysis); Palmer (a rural site aimed at monitoring and assessing the impacts of plumes from power stations on forest plantations in the region); and Leandra (set up to determine corresponding reduction in air pollution as a result of the electrification of a township).

\subsubsection{Elandsfontein}

Elandsfontein monitoring station was commissioned in May 1985. Due to its central location in the Highveld and the large amount of historical data, this site is considered to be of prime importance to regional impact studies and pollution 
trend analysis. Long-term trend analyses of sulphur dioxide (figure 2) indicate a slight increase in concentration levels over the past twenty years covering the south west to northern wind sectors. Concentration levels of nitrogen oxides levels recorded at Elandsfontein have been decreasing with time. The reduction in NOx concentrations is possibly due to the mothballing of older power stations in central Mpumalanga. Fine particulate matter levels recorded at Elandsfontein indicate increasing levels of particulates due to increases in domestic combustion largely due to low cost housing developments and increased squatter areas in the region.

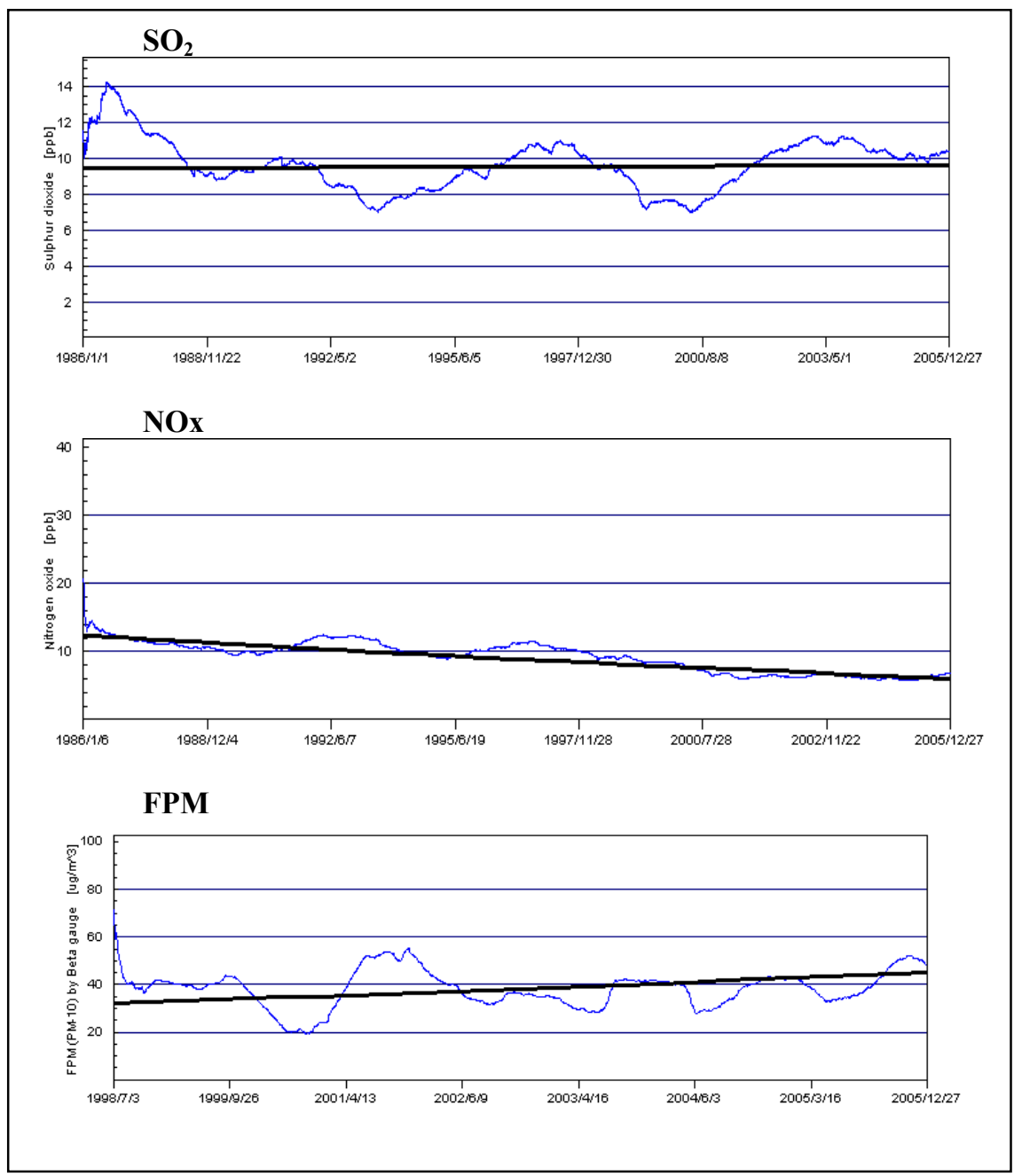

Figure 2: $\quad$ Elandsfontein long term trends from all wind sectors (1986-2005). 


\subsubsection{Palmer}

Air quality monitoring at Palmer monitoring station began in 1989 for 15 years. This site was set up specifically to monitor the impact of plumes from central Mpumalanga on the eastern Escarpment forest plantations. Concentrations of $\mathrm{SO}_{2}$ and NOx levels have been decreasing with time (figure 3) and increases of FPM were recorded at Palmer as was seen at Elandsfontein. FPM at Palmer only began in 1997; 8 years after monitoring of other pollutants began.

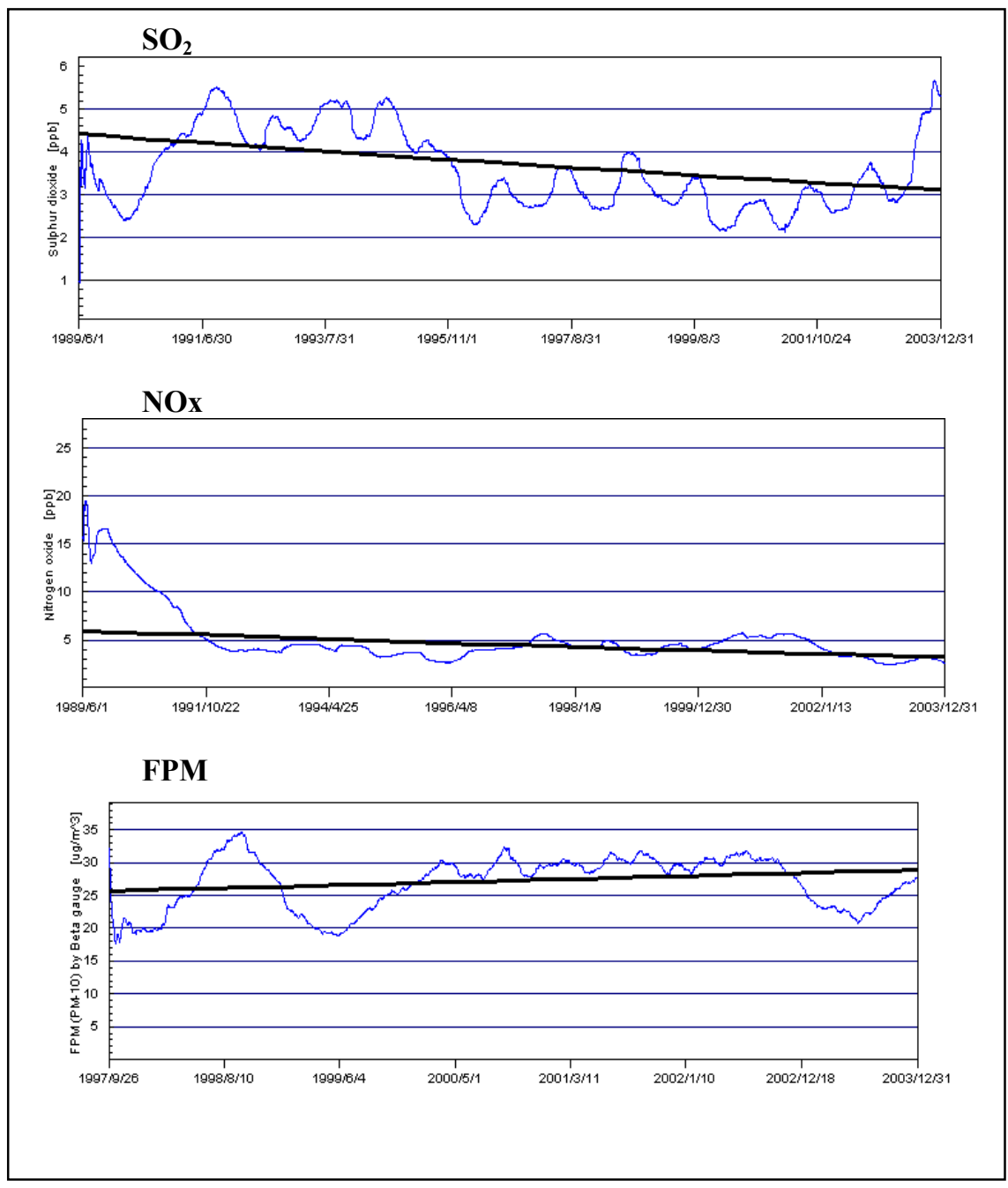

Figure 3: $\quad$ Palmer long term trends from all wind sectors (1989-2003 for $\mathrm{SO}_{2}$ and NOx) and 1997-2003 for FPM. 


\subsubsection{Leandra}

Monitoring at Leandra has been ongoing since 1995. This site was located downwind of a township to monitor changes in pollution levels with the introduction of electricity to the area. Electrification of households in Leandra and possibly the use of more efficient methods of domestic fuel usage, like the "basa njengo magogo" initiative in neighbouring townships, have resulted in decreased ambient SO2 and FPM concentrations in this area (figure 4).

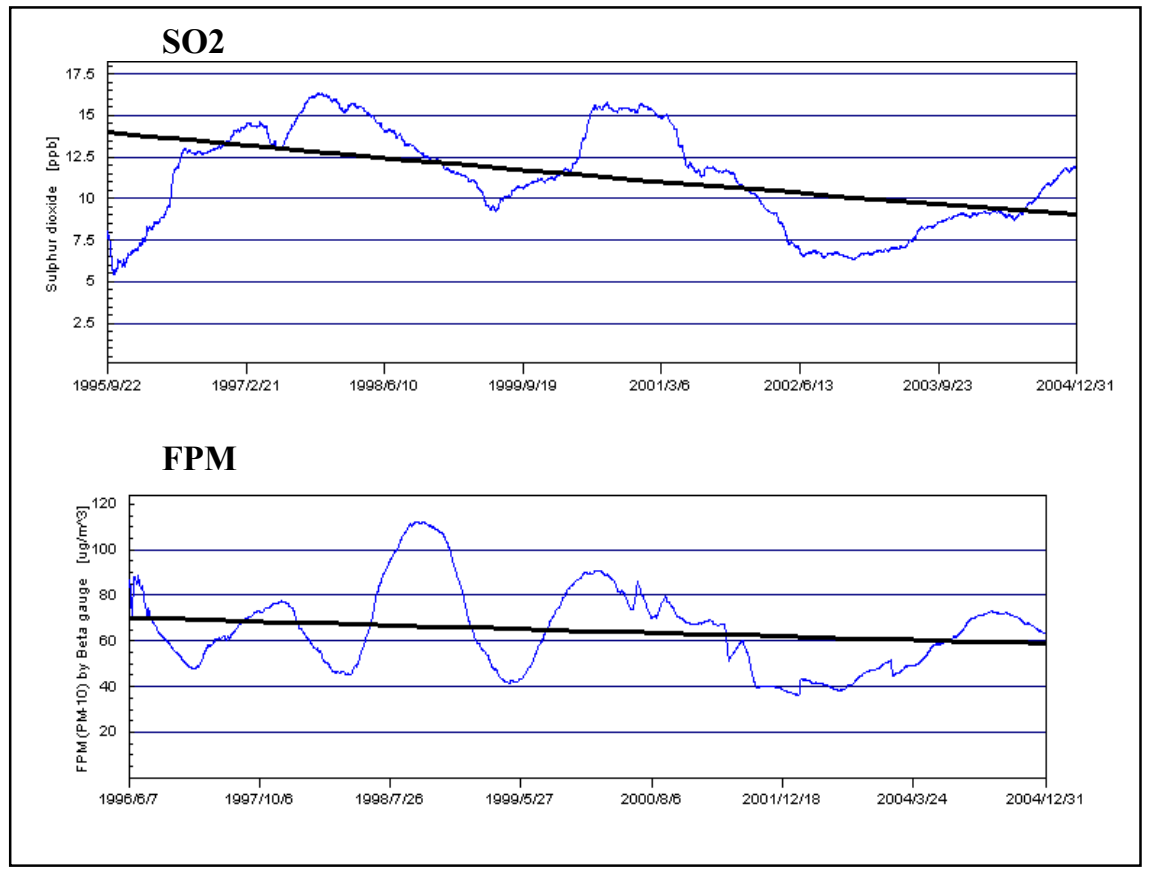

Figure 4: $\quad$ Leandra long term trends from all wind sectors (1996-2004).

\section{Air pollution control strategies}

Eskom's approach to emission control technology was previously centred on particulate emission management. In 1988 Eskom implemented a major emission reduction program aimed at retrofitting appropriate technologies to reduce emissions at existing plant. This reduced total emissions by $88 \%$ whilst in the same period generation of electricity increased by $48 \%$. Eskom's operating units have been retrofitted with Pulse Jet Fabric Filters, and $66 \%$ of the remaining Electrostatic Precipitators have had their performance improved by flue gas conditioning. Low NOx boilers have been introduced on all Eskom power stations.

Research has strengthened and complimented this program and also kept cognizant with emerging technologies. Several research projects have and continue to focus on the reduction of gaseous emissions using technologies that 
are best suited to the local environment and to resource availability. It is planned that any future expansion will require the reduction of sulphur dioxide, nitrogen oxides in addition to particulate removal. Another principle is that only proven and reliable technologies will be utilised and in many cases this has required up front research, testing and modelling in order to demonstrate the effectiveness of the technology (Hansen [8]).

Eskom's current air quality strategy is based on 3 principles; ensuring that Eskom's emissions to atmosphere, whether from power station stacks or from other sources, are managed to acceptable levels; ensuring that Eskom complies with all legally binding regulations and ensuring that Eskom's operations are sustainable in the short, medium and long term (Turner [9]).

\section{References}

[1] Rorich, R.P. \& Galpin, J.S., Air Quality in the Mpumalanga Highveld region, South Africa. South African Journal of Science, 94, pp 109-114, 1998

[2] Eskom power stations, www.eskom.co.za.

[3] Eskom 2002 Environmental report, Johannesburg, www.eskom.co.za.

[4] van Tienhoven, A. and Fey, M.V., Air pollution impacts on local soil properties near a power station in South Africa. Proceedings of the $11^{\text {th }}$ World Clean Air and Environment Congress, Durban, 13-18 September 1999

[5] Held, G., Schiefinger, H. \& Snyman, G., Recirculation of pollutants in the atmosphere of the South African Highveld, South African Journal of Science, 90, pp 91-97, 1994

[6] Eskom Annual ambient air quality data report. Johannesburg, South Africa, www.eskom.co.za.

[7] Turner, C.R., Personal communication, 4 April 2007, Corporate Consultant, Eskom, South Africa.

[8] Hansen, R.S., Personal communication, 29 March 2007, Independent consultant, Air pollution control technologies, South Africa.

[9] Turner, C.R., air quality significant achievements. Proceedings of the $1^{\text {st }}$ ERID air quality gap analysis workshop, Midrand, 4-6 April 2007. 